\title{
Farklı kalp hastalığı tanılı Türk kadınların cinsel fonksiyonlarının hastalık öncesi ve sonrası eșleri ile birlikte değerlendirilmesi: Kontrol gruplu çalıșma
}

\author{
Assessment of sexual functions of Turkish women with different heart diseases \\ before and after disease with their spouses: A study with a control group
}

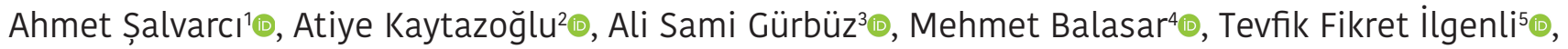
Mehmet Çolakoğlư(i)

\section{öz}

AMAÇ: Farklı kalp hastalığı olan Türk kadınları ve eşlerinin cinsel yaşamları sorgulanacaktır. Hastalık öncesi, sonrası ve kontrol grubuyla farklar değerlendirilecek.

GEREC ve YÖNTEM: Hastaların ve eșlerin ürolojik, hastaların kardiolojik, kadın doğum muayeneleri yapıldı. Tümünün hormonal, biokimyasal, mikrobiolojik değerlerine bakıldı. Beck depresyon envanteri (BDÖ) ile psikolojik durumları değerlendirildi. Kalp hastası kadınların Eastern Cooperative Oncology Group (ECOG) ile fiziksel performansları değerlendirildi. Kadın cinsel işlev ölçeği (FSFI), uluslar arası erektil işlev formu (IIEF) Türkçe versiyonu ile cinsel yaşamları sorgulanıldı. BDÖ >17 olan hastalar çalışmaya alınılmadı.

BULGULAR: Anjina pektoris, anjio, stent, kalp pili, bypass cerrahisi, mitral, aort kapak cerrahisi, akut myokard infaktüsü, konjestif kalp yetmezliği, kardiomyopati tanılı $\mathrm{n}=60$ kadın incelenildi. Menopoz, kalp hastalığı ve ek komorbiditesi olmayan $\mathrm{n}=45$ kadın ve eşleri kontrol grubu olarak seçildi. Hastalar ve kontrol grubunda erkek yaşları, menstrial siklus, sigara içme oranı, FSH, LH, E2, PRL, TT, TSH, ST3, ST4 değerlerinde anlamlı ( $>>0,05)$ farklılıklar gözlenilmedi. ECOG derecesi kontrol grubunda $\mathrm{p}<0,05$ yüksekti. Hastaların total FSFI skoru kontrol grubundan $\mathrm{p}<0,05$ düşüktü. Hastaların eşlerin total IIEF skoru kontrol grubundan $\mathrm{p}<0,05$ düşüktü. Hasta grubunda BDÖ toplam skoru kontrol grubundan $\mathrm{p}<0,05$ yüksekti.

SONUÇ: Farklı kalp hastalığı tanılı Türk kadınların ve eşlerinin kontrol gruplarına göre cinsel fonksiyon bozukluklarının belirgin yüksek olduğu gözlenildi. Hastalık tanısı konulunca, invaziv, noninvaziv yaklaşımlar sonrası, erken, geç dönemde eşlerin cinsel yönden takibi ve güvenli cinsel yaşam destek bilgisi verilmesi önemlidir.

Anahtar Kelimeler: Türk kadınları, kalp hastalı̆̆ı, seksüel disfonksiyon

\section{ABSTRACT}

OBJECTIVE: The sexual lives of Turkish women with different heart disease and their spouses will be questioned. Differences will be evaluated with the control group before and after the disease.

MATRERIAL and METHOD: The patients and their spouses underwent urological examinations and cardiological and obstetrics examinations of patients were performed. The hormonal, biochemical and microbiological values of all patients and their spouses were examined. Their psychological status was evaluated with Beck Depression Inventory (BDI). Physical performance of women with heart disease was evaluated with Eastern Cooperative Oncology Group (ECOG). Their sexual lives were assessed with the Turkish version of the Female Sexual Function Scale (FSFI) and the International Erectile Function (IIEF) form. Both male and female patients with $\mathrm{BDI}>17$ were excluded from the study.

RESULTS: A total of $\mathrm{n}=60$ women with angina pectoris, who underwent angiogram, stent, pacemaker, bypass surgery, mitral, aortic valve surgery, had acute myocardial infarction, congestive heart failure, and cardiomyopathy were studied. $\mathrm{N}=45$ women without menopause, heart disease and additional comorbidities and their spouses were selected as the control group. In patients and control groups, no significant differences were observed in terms of the age of men, menstrual cycle, smoking rate, FSH, LH, E2, PRL, TT, TSH, ST3 and ST4 values. The ECOG rate was higher than $\mathrm{p}<0.05$ in the control group. Total FSFI score of the patients was $\mathrm{p}<0.05$ lower than the control group. The total IIEF score of the spouses of the patients was $p<0.05$ lower than the control group. In the patient group, the total BDI score was higher than that of the control group, with $\mathrm{p}<0.05$.

CONCLUSION: It was observed that sexual dysfunctions were significantly higher in Turkish women with different heart disease and their spouses compared to the control groups.

Keywords: Turkish women, heart diseases, sexual dysfunctions
${ }^{1}$ Novafertil Tüp Bebek Merkezi, Üroloji Bölümü, Konya, Türkiye ${ }^{2}$ Novafertil Tüp Bebek Merkezi, Psikoloji bölümü, Konya, Türkiye ${ }^{3}$ Novafertil Tüp Bebek Merkezi, Kadın Doğum Bölümü, Konya, Türkiye ${ }^{4}$ Necmettin Erbakan Üniversitesi, Üroloji Anabilim Anabilim Dalı, Konya, Türkiye ${ }^{5}$ Selçuk Üniversitesi Tıp Fakültesi, Kardioloji Anabilim Dalı, Konya, Türkiye ${ }^{6}$ Necmettin Erbakan Üniversitesi Tıp Fakültesi, Kadın Doğum Anabilim Dalı, Konya, Türkiye

Yazışma Adresi/ Correspondence:

Uzm. Dr. Ahmet Şalvarcı

Orgeneral Tural Mh Meram Yeni Yol No 7542060 Meram, Konya, Türkiye

Tel: $\quad$ +903323235151

E-mail: drsalvarci@hotmail.com

Geliş/ Received: $\quad 13.03 .2020$

Kabul/ Accepted: $\quad 17.05 .2020$

\section{Gíniș}

Cinsel sağlık, somatik, entelektüel, zihinsel, duygusal ve sosyal yönlerini içeren genel sağlığın en önemli unsurlarından biridir. Kalp hastalıklarının cinsel yaşamla birlikte hayat kalitesini olumsuz etkilediği artık kesin olarak kabul edilmektedir. ${ }^{[1]}$ Cinsel ilgide azalma \%47-82, cinsel aktivite sıklı̆̆ında azalma \%48-76, cinsel performans ile ilgili olumsuz değişiklikler \%29,5-33 ve cinsel aktiviteden memnuniyetsizlik \%34-83 kalp hastası kadın ve erkelerde gözlenebilir. ${ }^{[2]}$ Kalp problemlerini ortaya çıkarma korkusu 
nedeniyle kişiler cinsellikten uzaklaşabilir. ${ }^{[3]} \mathrm{Bu}$ durum kadınlarda erkeklerden daha çok gözlenir. ${ }^{[4]}$ Özellikle kalp hastası kadınların \%48'inin taburculuktan bir ay sonra, \%70'inin 18 ay sonra hala cinsel aktivite ile ilgili sorunlar yaşadığı belirtilmiştir. ${ }^{[5]}$ Cinsel disfonksiyon yaşayan kadınların yalnızca \%18'i şikâyetlerini hekimlerine söylediği düşünüldüğünde, konunun sorgulaması, çözülmesi önem kazanmıştır. ${ }^{[6]}$ Ama diğer bir sorun da kadın cinsel fonksiyon bozukluğunun sorgulanmasının kadınlar ve hekimler için oldukça güç bir konu olmasıdır. Çalışmada farklı kalp hastalığı olan Türk kadınların cinsel yaşamları eşleri ve kontrol grupları ile değerlendirilmiştir.

\section{GEREÇ VE YÖNTEM}

Necmettin Erbakan Üniversitesinden 2016/701 sayılı ile 21/06/2016 tarihinde etik izni alındı. Kognitif fonksiyonları normal, önceden cinselliği engelleyecek herhangi bir cerrahi girişim geçirmemiş, menopozda olmayan, cinsel olarak aktif $n=60$ kalp hastası kadın ve eşleri sorgulandi. Hasta ve kontrol grubu eşlerinin International index of erectile function (IIEF) sorgulamalarında erektil fonksiyonu <22 olanlar ve hastalık öncesi orgazmik işlev, cinsel istek ve genel memnuniyetsizlik olanlar çalışmaya ilave edilmedi. Yine menopoz, kalp hastalığı ve ek komorbiditesi (hipertansiyon, Diabetes Mellitus, endokrin hastalığı vs.) olmayan, cinselliği engelleyecek bir ilaç kullanmayan ve cerrahi girişim geçirmemiş sağlıklı $n=45$ kadın ve eşleri kontrol grubu olarak seçildi. Bu hastaların kardiolojik değerlendirilmesine gerek görülmedi. Folikül stimule edici hormon (FSH), estradiol (E2), total testosteron (tt), prolaktin (PRL), free tiroksin 3,4 (fT3, fT4), tiroit stimule edici hormon (TSH), üre, kreatin, açlık kan şekerleri, kan lipid profilleri, karaciğer fonksiyon testleri ölçüldü. Beck depresyon ölçeği (BDÖ) ile psikolojik sorgulamaları yapıldı. İlk 18 soru dişında 19, 20, 21. Sorular cinsel yaşama yönelik olması nedeniyle ayrıca değerlendirildi. ${ }^{[7]}$ Depresyonun cinsellik üzerindeki olumsuz etkisi nedeniyle $B D O ̈>17$ olan hastalar çalışma dışı bırakıldı. ECOG (Eastern Cooperative Oncology Group) ile fiziksel perfomansları sorgulanıldı. ${ }^{[8]}$ Kadinların female sexual function index (FSFI) (full scale score range; 2-36), erkekler International index of erectile function (IIEF) (full scale score range; 1-30) ile değerlendirildi. Hem FSFI hem IIEF de yüksek skor cinsel işlevlerin iyi olduğunu gösterdi.

\section{İstatistiksel Yöntem}

Verilerin tanımlayıcı istatistiklerinde ortalama, standart sapma, medyan en düşük, en yüksek, frekans ve oran değerleri kullanıldı. Değişkenlerin dağılımı KolmogorovSimirnov test ile ölçüldü. Nicel bağımsız verilerin analizinde Mann-Whitney U test kullanıldı. Nitel bağımsız verilerin analizinde ki-kare test kullanıldı. Analizlerde SPSS 26,0 programı kullanıldı

\section{SONUÇLAR}

Haziran 2018-Ocak 2020 yılları arasında tamamen Türk kadınlarından oluşan hastaların demografik özellikler, ECOG, mensturial durumları, hormonları, FSFI, IIEF ve $B D O ̈$ değerleri Tablo 1'de kontrol grubunun ise Tablo 2 ve 3 'te verildi. Kalp hastası ve kontrol grubu arasında, histerektomi, alkol tüketimi, evlilik durumu ve nörolojik değerlendirme, pelvik cerrahi öyküsünde cinselliği etkileyecek farklılık izlenilmedi. Yine hipertansiyon, diyabet, dislipidemi tedavisi alanlar (FSFI 19,2 $\pm 1,2)$ ile almayanlar $(F S F I 20,1 \pm 1,1)$ arasında FSFI değerlerinde farklılık gözlenmedi $(\mathrm{p}>0,05)$.

\section{Kalp Hastası Kadınların Özellikleri}

Sorgulamada akut hastalık sonrası kadınlar $17 \pm 11$ aylık dönem içinde idi. $\mathrm{n}=28 / 60(\% 46,6)$ anjina pektoris, anjiyo, stent, kalp pili var idi. $\mathrm{n}=16 / 60(\% 26,6)$ bypass cerrahisi, $n=4 / 60(\% 6,69)$ mitral, aort kapak cerrahisi geçirmişti. $n=3 / 60$ (\%5) akut miyokard infaktüsü (AMI), $\mathrm{n}=9 / 60$ (\%15) konjestif kalp yetmezliği (KKY), kardiomiyopati (KMP) var idi. Hastaların vücut kitle indeksi (VKI) \%80 (n=48/60) 18,5-24,9 aralığında, \%11,6 $(\mathrm{n}=7 / 60) 25-29,9$ aralığında, \%8,3 $(\mathrm{n}=5 / 60)<18,5$ altındaydı. Kontrol grubunun vücut kitle indeksi (VKİ) \%78 ( $n=35 / 45)$ 18,5-24,9 aralığında, \%13 (n=6/45) 25-29,9 aralığında ve \%6,6 $(\mathrm{n}=3 / 45)$ ise $<18,5$ idi. VKI'leri arasinda istatiksel farklılık gözlenmedi (Tablo 2) ( $>>0,05)$. Hastaların $\mathrm{n}=43 / 60 \quad(\% 71,6)$ hiperlipidemi, $\mathrm{n}=42 / 60$ $(\% 53,3)$ hipertansiyon ve $\mathrm{n}=23 / 60$ (\%38) Tip I-II Diabetes Mellitus var idi. Daha önce sigara içen $n=13 / 21$ ü hastalık sonrası bırakmıştı. Hastalardan n=57/60 $(\% 95,4)$ beta blokür, antilipidemik, $n=40 / 60(\% 66,6)$ aldesteron antagonistleri ve anjiotensin-konverting enzim inhibitorü (ACE II), kardiak glikozid, $\mathrm{n}=46 / 60$ (\%77) diüretik, n=38/60 (\%38) antidiabetik ve insülin kullanıyor idi. Cinsel olarak aktif olduklarını söyleyen ECOG IV ileri evre kalp hastalığındaki kadınların seksüel yaşamı değerlendirmek için çalışmaya ilave edildi (Tablo 2). Kontrol grubu, hasta kadınlar ve eşlerin ürogenital muayeneleri normal idi. Hastaların ve kontrol grubunun hormonal değerleri, böbrek, karaciğer fonksiyonları ve mikrobiyolojik testleri normal izlendi (Tablo 1). 
Tablo 1. Hastaların ve eşlerinin demografik özellikleri. ECOG, hormonal değerleri, FSFI, IIEF, BDÖ skorları

\begin{tabular}{|c|c|c|c|c|c|}
\hline & Min - Max & Ortalama & \multicolumn{2}{|c|}{ Mean $\pm s d / n$} \\
\hline & $26,0-50,0$ & 43,0 & \multicolumn{2}{|c|}{$42,1 \pm 5,1$} \\
\hline \multicolumn{2}{|l|}{ Erkek yaş } & $31,0-58,0$ & 46,0 & \multicolumn{2}{|c|}{$46,1 \pm 6,2$} \\
\hline \multicolumn{2}{|c|}{ Evlilik Süresi } & $3,0-30,0$ & 18,0 & \multicolumn{2}{|c|}{$16,8 \pm 5,7$} \\
\hline \multirow[t]{4}{*}{ ECOG } & I & & & 50 & $47,6 \%$ \\
\hline & II & & & 39 & $37,1 \%$ \\
\hline & III & & & 11 & $10,5 \%$ \\
\hline & IV & & & 5 & $4,8 \%$ \\
\hline \multirow{2}{*}{$\begin{array}{l}\text { Menstrial } \\
\text { Siklus }\end{array}$} & Normal & & & 53 & $88,3 \%$ \\
\hline & Irregular & & & 7 & $11,7 \%$ \\
\hline \multirow[t]{2}{*}{ Sigara } & $(-)$ & & & 54 & $90,0 \%$ \\
\hline & $(+)$ & & & 6 & $10,0 \%$ \\
\hline \multicolumn{2}{|c|}{$\mathrm{FSH} \mathrm{mlU} / \mathrm{ml}$} & $1,9-32,0$ & 5,9 & \multicolumn{2}{|c|}{$7,2 \pm 5,3$} \\
\hline \multicolumn{2}{|l|}{$\mathrm{LH} \mathrm{mIU} / \mathrm{ml}$} & $2,3-22,4$ & 5,6 & \multicolumn{2}{|c|}{$6,2 \pm 3,4$} \\
\hline \multicolumn{2}{|l|}{$\mathrm{E} 2 \mathrm{pgr} / \mathrm{ml}$} & $7,0-101,3$ & 69,6 & \multicolumn{2}{|c|}{$65,9 \pm 25,0$} \\
\hline \multicolumn{2}{|c|}{ PRL mIU/ml } & $0,8-22,0$ & 11,3 & \multicolumn{2}{|c|}{$11,1 \pm 5,3$} \\
\hline \multicolumn{2}{|c|}{$\mathrm{tt} \mathrm{ng} / \mathrm{ml}$} & $0,1-1,3$ & 0,5 & \multicolumn{2}{|c|}{$0,6 \pm 0,3$} \\
\hline \multicolumn{2}{|c|}{$\mathrm{TSH} \mathrm{mlU} / \mathrm{ml}$} & $0,3-318,0$ & 3,2 & \multicolumn{2}{|c|}{$6,1 \pm 30,8$} \\
\hline \multicolumn{2}{|l|}{ sT3 ng/mll } & $0,1-2,0$ & 0,6 & \multicolumn{2}{|c|}{$0,7 \pm 0,4$} \\
\hline \multicolumn{2}{|c|}{ sT4 mcg/dl } & $3,0-10,3$ & 6,4 & \multicolumn{2}{|c|}{$6,4 \pm 2,0$} \\
\hline FSFI & & & & & \\
\hline Arzu etmel & & $0,6-4,8$ & 1,8 & & 1,6 \\
\hline Uyarılma & & $0,3-3,0$ & 2,1 & & $=0,8$ \\
\hline Vajinal Kay & sanlık & $0,3-3,6$ & 3,0 & & $=0,8$ \\
\hline Orgazm & & $0,4-4,4$ & 4,0 & & 1,2 \\
\hline Memnuniy & & $0,8-5,2$ & 3,2 & & $=1,1$ \\
\hline Ağrı & & $1,2-5,2$ & 3,2 & & $=1,2$ \\
\hline Total FSFI & & $9,8-25,9$ & 16,0 & & $\pm 4,0$ \\
\hline IIEF & & & & & \\
\hline Ereksiyon & & $21,0-29,0$ & 26,0 & & $\pm 2,4$ \\
\hline Orgasm & & $5,0-9,0$ & 9,0 & & $=1,2$ \\
\hline Arzu etmel & & $2,0-9,0$ & 8,0 & & 1,3 \\
\hline Seksüel Me & mnuniyet & $0,0-15,0$ & 5,0 & & 5,8 \\
\hline Genel Men & nuniyet & $2,0-10,0$ & 4,0 & & $=3,3$ \\
\hline BDÖ & & & & & \\
\hline Total & & $0,0-17,0$ & 13,0 & & $=6,0$ \\
\hline 1-18. soru & & $0,0-9,0$ & 6,0 & & 2,5 \\
\hline $19,20,21 \mathrm{sc}$ & rular & $0,0-9,0$ & 6,0 & & $=3,9$ \\
\hline
\end{tabular}

Beck depresyon ölçeği (BDÖ); 19. (sağık durumum kafama o kadar takılıyor ki, başka hiçbir şey düşünemiyorum), 20. (sekse olan ilgileri ve endişeleri), 21. (kalp hastalığı ve hayat için kendini cezalandırma). Eastern Cooperative Oncology Group (ECOG) skorları; 0: Tamamen aktiftir, tüm hastalık öncesi performansları kısıtlama olmadan sürdürebilir. 1: Fiziksel olarak yorucu bir faaliyetle sınırlıdır, ancak gezici ve hafif veya hareketsiz bir doğanın işlerini yürütebilir, örneğin, hafif ev işi, ofis işi. 2: Gezici ve tüm öz bakım yeteneğine sahip, ancak herhangi bir iş aktivitesini gerçekleştiremez. Uyanma saatlerinin \%50'sinden fazlası mobilize. 3: Sadece sınırı kişisel bakım yeteneğine sahip, uyanma saatlerinin $\% 50$ 'sinden fazlasını yatağa ya da sandalyeye bağımlı. 4: Tamamen yatak veya sandalye ile sınırlı. Female sexual function index (FSFI); Desire ve Arousal, Lubrication, Orgasm, Pain için skor range sırasıyla 1,2-6 ve $0-6$, Satisfaction için $0,8-6$ ve full FSFI scale score range; $2-36$. International index of erectile function (IIEF) değerlendirmede; Ereksiyon şikayeti; 0-10 ciddi, 11-16 orta, 17-21 hafif-orta, 22-25 hafif, 26-30 yok, Orgasm skoru 0-10, desire skor 2-10, sexual satisfaction skor 0-15, general satisfaction skoru 2-10 skor ve ful IIEF scale score range; $1-30$. Folikül stimule edici hormon (FSH), estradiol (E2), total testosteron (tt), prolaktin (PRL), Free troksin (fT3), free troksin (fT4), Tiroit stimüle edici hormon (TSH).
Kalp Hastası Kadınların Hastalık Öncesi ve Sonrası Cinsel Yașamları ve İstatistiksel Farkları

Kalp hastalığı tanı öncesi \%92'sinin ( $\mathrm{n}=55 / 60)$ ilişki sayısı ayda ortalama $5 \pm 2$ olduğu öğrenildi. Bypass ve KKY olan ECOG IV hastaların kalp hastalığı tanı öncesi ayda ilişki sayıları ise $3 \pm 1$ idi. İstatistiksel olarak tüm hastaların kalp hastalık tanısı öncesi ve sonrasına göre cinsel ilişki sayılarında (öncesi $5 \pm 3$, sonrası $2 \pm 1$ /aylık) belirgin düşüşler olduğu gözlendi $(p<0,05)$. Kalp hastası kadınların erkeklerinde hastalık öncesi ve sonrası sırasıyla ereksiyonda zorlanma $\mathrm{n}=5 / 60(\% 8,3)$ ve $\mathrm{n}=7 / 60(\% 11,6)$ ayn $(\mathrm{p}>0,05)$ iken, erken boşalma $\mathrm{n}=15 / 60(\% 25)$ den $\mathrm{n}=22 / 60(\% 36,6)$ ye, cinsel istekte azalma $\mathrm{n}=12 / 60(\% 20)$ den $\mathrm{n}=39 / 60(\% 65)$ a, seksüel memnuniyette azalma $n=9 / 60(\% 15)$ den $n=20 / 60$ $(\% 33,3)$ 'e yükseldiği gözlendi $(p<0,05)$. Özellikle erken boşalmadaki artış, cinsel istekte ve seksüel memnuniyetteki azalma, AMI, angina pektoris, balon, stent uygulananların eşlerinde daha fazla izlenildi. Kontrol grubunda ise \%51'de yaşam boyu erken boşalma olduğu öğrenildi. Kalp hastaların \%63'ü $(\mathrm{n}=38 / 60)$ invaziv/noninvaziv girişimler sonrası ilk $6 \pm 3$ aylık dönemde cinsel ilişkiyi hiç düşünmediklerini ve özellikle ilk 2 aylık dönemde \%66,6 ( $\mathrm{n}=40 / 60)$ sı ölüm korkusu ile yaşadıklarını ifade ettiler. İlk altı aylık dönemde $\% 28(\mathrm{n}=17 / 60)$ asla eşleri ile cinsellik konusunda tartışmaya, konuşmaya gerek bile olmadığını, cinsellik düşünecek halleri olmadığını ifade ettiler. AMI sonrası \%33'ü $(\mathrm{n}=1 / 3)$ bir yıl boyunca hiç cinsel aktivitede bulunmamışlardı. \%43,2'sinde $(\mathrm{n}=26 / 60)$ kendilerince cinsel aktivite kısıtlaması yaptığı gözlendi. \%18,3 ( $\mathrm{n}=11 / 60)$ hastalığına bağlı (daha çok KKY, AMI lı bazı hastalar ile ECOG yüksek olanlar) cinsel aktivitede sürekli şikâyetlerinin ortaya çıktığını söyledi. Hastaların \%62'si ( $\mathrm{n}=39 / 60)$ cinsel aktivite sırasında oluşabilecek hastalığa ait bulgularla nasıl başa çıkacaklarını, \%50'si (n=30/60) ise ilişkide eşleri ile hastalıklarında dolayı nasıl bir iletişim kuracağı endişesi taşıyor idi. Yüzde 25’i $(n=15 / 60)$ ilişki öncesi ve sırasında iletişim kuracağı veya bilgi alabileceği kişilerin olup olmadığını sordu. Hiç biri karşılaşabilecekleri endişe, korku hatta depresif durumlar, kullandıkları ilaçların cinsel işlevler üzerindeki etkileri konusunda da aydınlatılmamışt1. Yüzde 12'si ( $\mathrm{n}=7 / 60)$ internetten hastalıkları ve cinsellik konusunda bilgi edinmeye çalıştıklarını söyledi. Yüzde 5'i $(n=3 / 60)$ ise endişeleri, korkuları için cinsel terapistler ve kalp doktorlarıyla görüştüklerini ifade ettiler.

\section{Hasta Kadınlar ve Kontrol Grubların BECK Depresyon Ölçeği (BDÖ)}

$B D O ̈$ Türkçe versiyonu ile yapılan sorgulamalarda ilk 18 soruda hastalarda ve eşlerinde gözlenenler daha çok 
Tablo 2. Hastalar ve kontrol grubu arasındaki demografik, ECOG, menstürial siklus, sigara ve hormonal değerlerdeki istatiksel farklar

\begin{tabular}{|c|c|c|c|c|c|c|c|c|}
\hline & & \multicolumn{3}{|c|}{ Kontrol Grup $n=45$} & \multicolumn{3}{|c|}{ Hasta Grup n=60 } & \multirow[b]{2}{*}{$p$} \\
\hline & & \multicolumn{2}{|c|}{ Mean $\pm s d / n-$} & Ortalama & \multicolumn{2}{|c|}{ Mean $\pm s d / n-$} & Ortalama & \\
\hline \multicolumn{2}{|l|}{ Yaş } & \multicolumn{2}{|c|}{$40,1 \pm 5,8$} & 41,0 & \multicolumn{2}{|c|}{$43,7 \pm 3,7$} & 44,0 & $0,001^{\mathrm{mm}}$ \\
\hline \multicolumn{2}{|l|}{ Erkek Yaş } & \multicolumn{2}{|c|}{$44,6 \pm 7,3$} & 45,0 & \multicolumn{2}{|c|}{$47,2 \pm 5,0$} & 48,0 & $0,079^{\mathrm{mm}}$ \\
\hline \multicolumn{2}{|l|}{ Evlilik süresi } & \multicolumn{2}{|c|}{$14,6 \pm 6,3$} & 16,0 & \multicolumn{2}{|c|}{$18,5 \pm 4,5$} & 19,0 & $0,000^{\mathrm{mm}}$ \\
\hline \multirow{4}{*}{ ECOG } & I & 33 & $73,3 \%$ & & 21 & $35,0 \%$ & & \multirow{4}{*}{$0,012^{x^{2} x^{2}}$} \\
\hline & II & 12 & $26,7 \%$ & & 27 & $45,0 \%$ & & \\
\hline & III & 0 & $0,0 \%$ & & 7 & $11,7 \%$ & & \\
\hline & IV & 0 & $0,0 \%$ & & 5 & $8,3 \%$ & & \\
\hline \multirow{2}{*}{ Menstrual Siklus } & Normal & 39 & $86,7 \%$ & & 53 & $88,3 \%$ & & \multirow{2}{*}{$0,674^{x^{2} x^{2}}$} \\
\hline & Irregular & 6 & $13,3 \%$ & & 7 & $11,7 \%$ & & \\
\hline \multirow{2}{*}{ Sigara } & $(-)$ & 40 & $88,9 \%$ & & 54 & $90,0 \%$ & & \multirow{2}{*}{$0,890^{x^{2} x^{2}}$} \\
\hline & $(+)$ & 5 & $11 \%$ & & 6 & $10,0 \%$ & & \\
\hline \multicolumn{2}{|l|}{$\mathrm{FSH} \mathrm{mIU} / \mathrm{ml}$} & \multicolumn{2}{|c|}{$6,5 \pm 4,2$} & 6,0 & \multicolumn{2}{|c|}{$7,6 \pm 5,9$} & 5,8 & $0,648^{\mathrm{mm}}$ \\
\hline \multicolumn{2}{|l|}{$\mathrm{LH} \mathrm{mIU/ml}$} & \multicolumn{2}{|c|}{$5,6 \pm 2,4$} & 4,7 & \multicolumn{2}{|c|}{$6,7 \pm 3,9$} & 5,8 & $0,130^{\mathrm{mm}}$ \\
\hline \multicolumn{2}{|l|}{$\mathrm{E} 2 \mathrm{pgr} / \mathrm{ml}$} & \multicolumn{2}{|c|}{$65,4 \pm 24,4$} & 68,6 & \multicolumn{2}{|c|}{$66,2 \pm 25,6$} & 69,8 & $0,632^{\mathrm{mm}}$ \\
\hline \multicolumn{2}{|l|}{ PRL mIU/ml } & \multicolumn{2}{|c|}{$10,7 \pm 4,9$} & 10,0 & \multicolumn{2}{|c|}{$11,3 \pm 5,6$} & 11,5 & $0,513^{\mathrm{mm}}$ \\
\hline \multicolumn{2}{|l|}{$\mathrm{TT} \mathrm{ng} / \mathrm{ml}$} & & & 0,5 & & & 0,5 & $0,438^{\mathrm{mm}}$ \\
\hline $\mathrm{TSH} \mathrm{mlU} / \mathrm{ml}$ & & & & 3,0 & & & 3,2 & $0,623^{\mathrm{mm}}$ \\
\hline sT3 ng/ml & & & & 0,6 & & & 0,6 & $0,669^{\mathrm{mm}}$ \\
\hline sT4 mcg/dl & & & & 6,4 & & & 6,1 & $0,488^{\mathrm{mm}}$ \\
\hline VKi kg/m² & & & & & & & & $0,633^{\mathrm{mm}}$ \\
\hline $\begin{array}{l}\text { mm Mann-Whitney U } \\
\text { Eastern Cooperative On } \\
\text { sinırlıdı, ancak gezici v } \\
\text { gerçeklesttiremez. Uyan } \\
\text { bağımlı. 4: Tamamen ya } \\
\text { stimüle edici hormon ( } \\
\mathrm{kg} / \mathrm{m} \text {. Folikül stimule e }\end{array}$ & $\begin{array}{l}\text { st } / X^{2} \text { Chi-squa } \\
\text { logy Group (E } \\
\text { lafif veya hare } \\
\text { a saatlerinin } 9 \\
\text { k veya sandal } \\
\text { H). VKi (Vücüt } \\
\text { i hormon (FSH }\end{array}$ & Folikü & $\begin{array}{l}\text { aktiftir, tüm } \\
\text { irütebilir, öt } \\
\text { 3: Sadece s } \\
\text { edici horm } \\
\text { in altinda is } \\
\text { steron (tt), }\end{array}$ & $\begin{array}{l}\text { lık öncesi perfor } \\
\text { hafif ev işi, ofis } \\
\text { isisel bakım yete } \\
\text {-1), estradiol (E2) } \\
\text { f.18,5-24,9 kg/r } \\
\text { tin (PRL), Free t }\end{array}$ & $\begin{array}{l}\text { II kisıtla } \\
\text { ezici ve } \\
\text { sahip, u } \\
\text { estoster } \\
\text { hda ise. } \\
\text { T3), free }\end{array}$ & $\begin{array}{l}\text { Idan sürdüre } \\
\text { akım yeten } \\
\text { aatlerinin \% } \\
\text { brolaktin (PR } \\
\text { kilolu. 25-2S } \\
\text { (fT4), Tiroit }\end{array}$ & $\begin{array}{l}\text { 1: Fiziksel olarak } \\
\text { sahip, ancak her } \\
\text { iden fazlasını yat } \\
\text { ee troksin (fT3), } \mathrm{f} \\
/ \mathrm{m}^{2} \text { arasında ise. } \\
\text { lle edici hormon }\end{array}$ & $\begin{array}{l}\text { bir faaliyetle } \\
\text { ir is aktivitesin } \\
\text { da sandalyeye } \\
\text { ksin (fT4), Tiroi } \\
\text { ilolu. 30-34,9 }\end{array}$ \\
\hline
\end{tabular}

endişe ağırlıklı iken, özellikle 19. -21. soruların cevaplarında kontrol gruplarından belirgin farklar var idi (Tablo3). Erkeklerin \%35'inin ( $\mathrm{n}=21 / 60)$ ilişki anında eşim kalp krizi geçirecek ve ölecek korkusu taşıdığı öğrenildi. Bu aynı zamanda ilişki sayısında azalmanın da sebebiydi. AMI, angina, anjiyo, stent, balon, by-pass olan hastaların eşlerinde $B D O ̈$ de" 5. Zaman zaman eşlerine karşı kötü davrandıklar1 için suçlu hissettiklerini, 20. Öncesine göre sekse ilgim az; sebep eşimin rahatsızlı̆̆ı" daha sık alınan cevaplar idi. Yine hastalar bu sorularda hastalıkla cezalandırıldıklarını, ilişkiyi çoğunlukla istemediklerini, eşlerine karşı cinsellik konusunda mahçupluk hissettiklerini söylediler.

\section{Kardiolojik Tanıya Göre FSFS/IIEF Skorları ve Kontrol Grup Arası İstatiksel Farklar}

Kalp hastası grupta FSFI değerleri; cinsel istekte azalma $\mathrm{n}=37(\% 61,6)$, uyarılma $\mathrm{n}=10(\% 16,6)$, vajinal kayganlık $n=9(\% 15)$, orgazm $n=22(\% 36,6)$, seksüel memnuniyeti $\mathrm{n}=9$ (\%15), ağrı $\mathrm{n}=8(\% 13,3)$, ilişkide azalma ve ilişkide nefeste zorlanma $\mathrm{n}=29(\% 48,3)$ olduğu öğrenildi. $E C O G$ IV olan hastalarda ilişki esnasında kalp şikâyetlerinin ortaya çıkabildiğini ifade ettiler. ECOG IV kadınların erkekleri ise ilişkiye daha çok eşi istediği zaman girdiklerini ve eşleri istekli olsa da şikayetlerin ortaya çıkması korkusu nedeniyle kendilerinin isteksiz olduklarını yeniden ilişkiyi hem kendileri hem de eşlerinin uzattıklarını ifade ettiler.

Her tanı için $F S F I$ ve $I I E F$ cinsel işlev skorlarına bakıldı. Genel kontrol grubu (FSFI 20,5 $\pm 3,1 /$ IIEF 14,3 $\pm 2,0$ ) ile kıyaslamalara göre; anjina pektoris, korener anjio, stent olanlarda FSFI 12 $\pm 2,4 /$ IIEF 2,2 $\pm 0,8$ kontrol grubunda düşük $(p<0,05)$ idi. By-pass cerrahisi geçirenlerde FSFI $19 \pm 2,2$ kontrol grubu ile aynı $(\mathrm{p}>0,05)$ ve normal iken, IIEF $22,2 \pm 1,8$ kontrol grubundan daha iyiydi $(p<0,05)$. AMI'da FSFI skoru15,41 $\pm 8,04 /$ IIEF $3 \pm 1$ kontrol grubunda düşük idi $(p<0,05)$. KKY de FSFI 10 $\pm 1,4 /$ IIEF $3,2 \pm 1,2$ kontrol grubundan düşük gözlendi $(p<0,05)$. 
Table 3. Hastalar ve kontrol grupları arasında FSFI, IIEF, BDÖ skorları arasındaki istatistiksel farklar

\begin{tabular}{|c|c|c|c|c|c|}
\hline & \multicolumn{2}{|c|}{$\begin{array}{c}\text { Control Group } \\
n=45\end{array}$} & \multicolumn{2}{|c|}{$\begin{array}{c}\text { Patient Groups } \\
n=60\end{array}$} & \multirow[b]{2}{*}{$p$} \\
\hline & Mean $\pm s d$ & Median & Mean $\pm s d$ & Median & \\
\hline \multicolumn{6}{|l|}{ FSFI } \\
\hline Arzu etmek & $4,2 \pm 0,7$ & 4,2 & $1,2 \pm 0,5$ & 1,2 & $0,029^{m m}$ \\
\hline Uyarılma & $2,3 \pm 0,6$ & 2,7 & $1,7 \pm 0,9$ & 1,2 & $0,000^{\mathrm{mm}}$ \\
\hline $\begin{array}{l}\text { Vajinal } \\
\text { kayganlık }\end{array}$ & $3,0 \pm 0,8$ & 3,0 & $2,5 \pm 0,8$ & 3,0 & $0,001^{\mathrm{mm}}$ \\
\hline Orgazm & $3,5 \pm 1,3$ & 4,0 & $3,1 \pm 1,1$ & 4,0 & $0,000^{\mathrm{mm}}$ \\
\hline Memnuniyet & $3,6 \pm 1,2$ & 4,0 & $3,0 \pm 1,0$ & 3,2 & $0,001^{\mathrm{mm}}$ \\
\hline Ağrı & $4,1 \pm 1,3$ & 4,4 & $2,8 \pm 0,8$ & 3,0 & $0,004^{\mathrm{mm}}$ \\
\hline Total FSFI & $20,5 \pm 3,1$ & 20,6 & $14,3 \pm 2,0$ & 14,6 & $0,000^{\mathrm{mm}}$ \\
\hline \multicolumn{6}{|l|}{ IIEF } \\
\hline Ereksiyon & $26,2 \pm 2,5$ & 26,0 & $25,8 \pm 2,4$ & 26,0 & $0,000^{\mathrm{mm}}$ \\
\hline Orgasm & $7,9 \pm 1,2$ & 8,0 & $8,1 \pm 1,2$ & 9,0 & $0,312^{\mathrm{mm}}$ \\
\hline Arzu etmek & $8,6 \pm 0,7$ & 9,0 & $7,6 \pm 1,4$ & 8,0 & $0,427^{\mathrm{mm}}$ \\
\hline $\begin{array}{l}\text { Seksüel } \\
\text { memnuniyet }\end{array}$ & $14,4 \pm 0,9$ & 15,0 & $3,1 \pm 1,6$ & 3,0 & $0,000^{\mathrm{mm}}$ \\
\hline $\begin{array}{l}\text { Genel } \\
\text { memnuniyet }\end{array}$ & $9,4 \pm 1,1$ & 10,0 & $3,1 \pm 0,8$ & 3,0 & $0,000^{\mathrm{mm}}$ \\
\hline \multicolumn{6}{|l|}{ BDÖ } \\
\hline Total & $3,1 \pm 2,1$ & 3,0 & $14,8 \pm 1,3$ & 15,0 & $0,000^{\mathrm{mm}}$ \\
\hline $\begin{array}{l}1-18 . \\
\text { sorular }\end{array}$ & $2,6 \pm 1,9$ & 2,0 & $6,7 \pm 0,9$ & 6,0 & $0,000^{\mathrm{mm}}$ \\
\hline $\begin{array}{l}19,20,21 \\
\text { sorular }\end{array}$ & $0,5 \pm 0,8$ & 0,0 & $8,1 \pm 1,2$ & 9,0 & $0,000^{\mathrm{mm}}$ \\
\hline \multicolumn{6}{|c|}{$\begin{array}{l}\text { m Mann-whitney U test } \\
\text { Female sexual function index (FSFI); Desire ve Arousal, Lubrication, Orgasm, Pain için } \\
\text { skor range sırasıyla 1,2-6 ve 0-6, Satisfaction için 0,8-6 ve full FSFI scale score range; } \\
2 \text { 2-36. International index of erectile function (IIEF) değerlendirmede; Ereksiyon şikayeti; } \\
0-10 \text { ciddi, } 11-16 \text { orta, } 17-21 \text { hafif-orta, } 22-25 \text { hafif, } 26-30 \text { yok, Orgasm skoru 0-10, } \\
\text { desire skor 2-10, sexual satisfaction skor 0-15, general satisfaction skoru 2-10 skor ve } \\
\text { full IIEF scale score range; } 1-30 \text { idi. Beck depresyon ölçeği (BDÖ); } 19 \text {. (sağlı durumum } \\
\text { kafama o kadar takillyor ki, başka hiçbir şey düşünemiyorum), 20. (sekse olan ilgileri ve } \\
\text { endişeleri), 21. (kalp hastalığı ve hayat için kendini cezalandırma). }\end{array}$} \\
\hline
\end{tabular}

KMP de FSFI 20,2 $\pm 2,4$ kontrol grubu ile ayn ( $>0,05)$ ve normal iken $I I E F 24,2 \pm 0,8$ ile kontrol grubundan daha iyiydi $(p<0,05)$. Kalp pili olanların FSFI $22,2 \pm 1,4$ kontrol grubuyla aynı $(\mathrm{p}>0,05)$ ve normal iken IIEF $23,2 \pm 1$ ile kontrol grubundan daha iyiydi $(p<0,05)$. Mitral, aort kapak cerrahili hastalarda FSFI 16,2 $\pm 2,4$ normal ve kontrol grubuyla aynı (p>0,05) iken IIEF 19,2 $\pm 1,2$ ile kontrol grubunda daha iyi $(p<0,05)$ gözlendi.

\section{TARTISTMA}

Kalp hastalığı cinsel fonksiyonlar önemli ölçüde bozulabilir. ${ }^{[9]}$ Cinselliğin ciddi efora yol açtığ ${ }^{1}$ ve yeterli efor kapasitesinin gerekli olduğu bilinmektedir. ${ }^{[10]}$ Kalp rahatsızlığ 1 şiddetiyle doğru orantılı olarak cinsel aktivitede hastaların problemleri de artabilir. ${ }^{[11]}$ Ayrıca kalp hastalığı tanısı, acil kardiyovasküler durum veya girişimsel işlem sonrası hem kadınlarda hem erkeklerde cinsel aktiviteyi azaltma veya uzaklaşma yönünde eğilimler olabilir. ${ }^{[10,11]}$

\section{AMI ve Cinsellik}

AMI sonrası cinsel fonksiyon bozukluğu kadınların $\% 80$ 'inde görüldüğü ve $\% 25$ 'inin cinsel aktiviteyi bıraktığı bildirilmiştir. ${ }^{[12]}$ Hastalarımızda ilk altı aylık dönemde literatürden daha yüksek oranda (\%100) cinsel fonksiyonu bıraktığı, \%33'ünün ise bir yıl boyunca hiç bir cinsel aktivitede bulunmadığı gözlenmiştir. Cinsel aktivitenin azalmasının ana nedenleri ilişkide ya kalp krizi geçireceği yada aniden ölebileceği endişesi olarak öğrenilmiştir. Bu endişeler diğer çalışmalar ile uyumlu bulunmuştur. ${ }^{[12,13]}$ Hastalarımızda memnuniyet ve ağrı dışında tüm ortalama $F S F I$ ve IIEF skorları kontrol grubundan daha düşük çıkmıştır $(p<0,05)$. Önceki çalışmalarla uyumlu olarak cinsel istek, uyarılma, vajinal kayganlık, orgazmik zorluklar olduğu görülmüştür. ${ }^{[1]]}$ Cinsel istek skoru diğer skorlardan kontrol grubuna göre çok daha belirgin düşük izlenmiştir $(p<0,05)$. Aylık cinsel ilişki sıklığı kontrol grubuna göre anlamlı derecede düşük bulunmuştur (1,4’e karşılık 4,14) $(p<0,05)$. Cinsel fonksiyon bozukluğunun bir yil sonra bile \%66 oranıyla devam ettiği gözlenmiştir. Bu literatürdeki \%32 den çok daha yüksek çıkmıştır. ${ }^{[12,13]}$

\section{Anjina Pektoris, Korener Anjiyo, Stent, By-pass Cerrahisi ve Cinsellik}

Anjina pektoris, korener anjiyo, stent, sonrası hastaların seksüel aktivitesinde $\% 63$ varan azalmalar izlenirken, bypass geçiren hastaların \%46'sında cinsel aktivitede herhangi bir değişiklik görülmemiş, \%36'sında cinsel ilişkiye girme sıklığında azalma, \%10'unda artma, \%8'inde ise işlem sonrası cinsel aktivitelerinin olmadığı önceki çalışmalarda saptanmıştır. ${ }^{[13]}$ Literatürden farklı olarak hastalarımızın \%50 sinde daha düşük oranla cinsel aktivitede azalma izlenmiştir. Yine \%25'inde ise literatürden düşük oranda cerrahi sonrası $5 \pm 3$ ay arası ilişki olmadığı gözlenmiştir. ${ }^{[13]}$ Bypass sonrası 6. aydan itibaren aylık ortalama 2,14 sıklıkla ilişki sayısı literatürden yüksek izlenilmiştir. ${ }^{[13]}$ Cerrahi sonrası erken ve geç dönemde (ilk 6 ay ve sonrası) \%50 oranı ile ilişki sıklığında artma literatürden daha yüksek olduğu bulunmuştur. ${ }^{[13,14]}$ Serimizde hastalar ve eşlerindeki cinsel ilişki korkusu, azalan cinsel istek ve seksüel memnuniyetin invaziv girişimle eşzamanlı arttığı ve düzeldiği önceki çalışmalar ile uyumlu görülmüştür. ${ }^{[14]}$ Anjina pektoris, korener anjio, stent olanlarda $F S F I$ ve IIEF skorları düşük iken bypass cerrahisi geçirenlerde literatürle uyumlu olarak normal bulunmuştur. ${ }^{[14]}$ Bunun sebebinin cerrahi sonrası 
verilen güvenli cinsel yaşam bilgilerinin olduğu anlaşılmıştır. Özellikle invaziv girişim sonrası eşlerinin \%70'i ilk 6 aylık dönemde cinsel ilişki istememeyi anlayışla karşıladıkları halde, hasta eşlerinin kendileri için hala strese girdiklerini ifade etmişlerdir.

\section{KKY/KMP Kadın Hastalar ve Cinsellik}

Cinsel ilgide ve aktivitede azalma KKY hastalarının \%60-87'sinde ilerleyen zamanla gözlenebilir. ${ }^{[15]}$ FSFI ve IIEF cinsel işlev skoru KKY'de diğer serilerle uyumlu olarak serimizde de düşük gözlenmiştir. ${ }^{[15]}$ Hastalarımızın \%44'ü cinselliğin KKY'ye etkisinin ne olabileceğini biliyor idi. Önceki çalışmalardaki \%21 [15] oranından daha yüksek $\% 33$ oranıyla ilişkide sürekli sorun yaşadıklarını, cinsel istekleri olduğu halde ilişkiden sık sık kaçındıklarını söylemişlerdir. Yüzde 61 oranıyla ilişki sıklığındaki belirgin azalma literatür ile uyumlu bulunmuştur. ${ }^{[15]} \mathrm{KKY} l i$ grubumuzda ilişki sırasında vajinal yağlanmada azalma ve buna bağlı orta/şiddetli ağrılı ilişki olduğunu diğer çalışmalar benzer çıkmıştır. ${ }^{[16]}$ Bunun kullanılan diüretiklerin yan etkisine bağlı olduğu yada KKY şikayetlerinin arttığı dönemde olduğu öğrenilmiştir. Tedavi sonrası \%33 ise literatürle uyumlu olarak ilişkide çıkan nefes darlıklarının kalmadığını ve ilişki sayılarının belirgin arttığını söylemiştir. ${ }^{[16]}$ KMP hastaları ise ilişki sırasında nefes darlığı dışında şikâyetleri olmadığını söylediler. FSFI ve IIEF skorları literatürle uyumlu olarak normal sınırlarda bulunmuştur. ${ }^{[17]}$ Diğer çalışmalarla uyumlu olarak cinsel aktivite için uygun olup olmadıkları bizde de efor testleri ile ayırt edilmiştir. ${ }^{[1]}$

\section{Kalp Pilli Kadın Hastalar ve Cinsellik}

Kalp pili takılan hastaların \%72'sinde cinsel memnuniyetin arttığı önceki çalışmalarda gözlenmiştir. ${ }^{[18]}$ Serimizde bu oran \%66 ile literatürden düşük çıkmıştır. Hastalar cinsel aktivitedeki çarpıntılarının kaybolduğunu pilden memnun kaldıklarını literatürle uyumlu olarak ifade etmişlerdir. ${ }^{[18]}$ $F S F I$ ve IIEF skorları tedaviler öncesi normal iken tedavi sonrasında da genel memnuniyet, cinsel isteğin artması literatür ile uyumlu bulunmuştur. ${ }^{[18,19]}$

\section{Kapak Hastalıklı Kadın Hastalar ve Cinsellik}

Protez kapak cerrahileri sonrası hastalarımızın cinsel aktivitelerinin arttığı literatürle uyumlu gözlenmiştir. ${ }^{[20]}$ Sonuçların kontrol gruplarından bile daha iyi olduğu önceki çalşsmalarla uyumlu bulunmuştur $(p<0,05){ }^{[20]}$ Cerrahi sonrası ilişkideki dispne ve göğüs ağrılarının olmadığı öğrenilmiştir. Özellikle IIEF de cinsel ilişkideki genel memnuniyetin cerrahi sonrası çok belirgin düzelmesi önceki çalışmalar ile uyumlu bulunmuştur. ${ }^{[20,21]}$

\section{Kalp Hastası Kadınların BDö Sonuçları}

Hastalarımızda $B D O ̈$ de endişe, depresyon ve beraberinde cinsel yaşamdaki olumsuzluklar \%83 oranı ile önceki çalışmalardaki \%58-72 oranından daha yüksek gözlenmiştir. ${ }^{[21]}$ Hastalıktan kaynaklanan endişe ve stres ilave cinsel işlevdeki azalmada eşler arasında ek endişe ve stresi doğurmuştur. Bunun da $B D O ̈$ skorlarında ek yükselmeye neden olduğu önceki çalışmalar ile uyumlu bulunmuştur. ${ }^{[21]}$ Eşler arasında en yaygın gözlenen endişe ve stres ilgi gösteremiyorum duygusu, ve ilişkide ne ile karşılaşırım düşüncesi olmuştur. AMI, bypass cerrahisi, anjina, balon, stent uygulamalarında $B D O ̈$ skorları ilk altı aylık dönemde önceki çalışmalarla uyumlu olarak daha yüksek bulunmuştur. ${ }^{[22]}$ Tedavi ile şikâyetlerin geçmesi ve cinsellik konusunda bilgilendirmeler sonucu ilişki sayılarının arttığı, $B D O ̈$ skorlarını normal sınırlara girdiği literatürle uyumlu gözlenmiştir. ${ }^{[22]}$

\section{Kalp Hastası Kadınlarda Kalp ilaçları ve Cinselliğe Etkisi}

Kardiyovasküler hastalıkların tedavisinde kullanılan ilaçlara bağlı cinsel istek ve orgazm problemleri, menstruasyon bozuklukları oluşturabilmektedir. ${ }^{[23]}$ Tiazidler ve aldosteron ile tedavilerde vajinal ıslanma veya adet düzensizlikleri ile ilgili sorunlar önceki çalışmalar ile uyumlu gözlenmiştir. $^{[24]}$ Topikal kremler ile bunlar düzeltilmiştir. Literatürle uyumlu olarak \%11,7 menstural bozukluğun yarısının kalp tedavisi sonrası aldıkları beta blokürler, ACE inhibitörleri ve trombolitik ilaçlarla ortaya çıktığ ${ }_{1}$ öğrenildi. ${ }^{[23]}$ Psikiyatrik tedavide kullanılan antipsikotik ilaçlar, SSRI, antidepresanlar ve monoamin oksidaz inhibitörlerinin cinsel istekte azalma, orgazm bozukluklarına neden oldukları bilinmektedir. ${ }^{[25]} \mathrm{Bu}$ nedenle psikiyatrik konsültasyonda, önceden verilen SSRI'lar yerine bupropion, moklobomid, mirtazapin türünde yeni jenerasyon cinsel yan etkisi düşük antidepresifler planlanmıştır. ${ }^{[26]}$ Beta bloker alan hastalarımızdaki $F S F I^{\prime}$ daki cinsel istekte azalma, ilgi azlığı ve cinsel memnuniyette azalma literatürle uyumlu bulunmuştur. ${ }^{[27]}$ Özellikle metoprolol ve atenolol alanlarda daha belirgin gözlenmiştir. ${ }^{[27]}$ Yine anjiotensin reseptör blokerleri alan hastalarımızda cinsel isteksizlik ve memnuniyetsizlik beta bloker alan hastalarda sorgulamada daha az gözlenmesi önceki çalışmalar ile uyumlu izlenmiştir. ${ }^{[28]}$ Bu nedenle kardiyolojik değerlendirmelerde ileri derecede FSFI bozukluğu olan, beta blokür ve ACE-II inhibitörü alan hastaların ilaçları anjiotensin reseptör blokerlerine çevrilmiştir. ${ }^{[28]}$

\section{Kalp Hastası Kadınlarda Cinsel Eğitim}

Hastaların \%33'ünde nasıl bir cinsel hayat yaşamalıyım endişesi literatürdeki \%11 oranından yüksek gözlenmiştir. 
[21] Sorgulamalarda hiçbir hastaya cinsel aktivite konusunda bilgi verilmediği sadece hekimleri tarafından iki ay ilişkinin yasaklandığı öğrenilmiştir. Önceki çalışmalar ile uyumlu olarak eşler arasında gereksiz endişe, korkuya sebep olmuş, cinsel aktivite kaybına yol açmış ve hastalar kendilerince cinsel hayat düzenlemesi yapmışlardır. ${ }^{[30]} \mathrm{Bu}$ yüzden taburculuk öncesi verilecek eğitimin sağlıklı bir cinsel aktivitenin yaşanmasında önemli rolü olduğu önceki çalışmalarda ifade edilmiştir. ${ }^{[21,29]}$

Çalışmanın kısıtlamalarından birisi özellikle KKY ve kapak replasman cerrahisi geçiren grupların tedavi öncesi efor kapasitelerine ulaşılamamasıdır. Gerek kalp hastası gerek kapak cerrahisi yapılan hastaların sorgulanma anında kompanse dönemde oldukları son efor kapasite testlerinde kardiyoloji tarafından söylenilmiştir. Bu yüzden tedavi öncesi cinsel yaşamlarının değerlendirmesinde ECOG, FSFI, IIEF sorgulamaları ön plana alınmıştır.

\section{SONUÇ}

Kalp hastası Türk kadınlarında ve eşlerinde cinsel işlev bozukluklarının kontrol gruplarına, önceki çalışmalara göre daha yaygın sorun olduğu ortaya konulmuştur. Özellikle AMI sonrası cinsel problemler kısa ve uzun dönemde literatürden daha yüksek oranda izlenmiştir. Anjina pektoris, koroner anjiyo, stent ve bypass cerrahisi geçiren hastalarda cinsel fonksiyon bozulması literatürden düşük izlenirken cerrahi sonrası ilk altı ayda ilişki sayısının literatürden fazla olduğu bulunmuştur. Tedaviler sonrasında seksüel yaşamların olumlu yönde gittiği gözlenmiştir.

\section{Etik Kurul Onayı}

Çalışma, Necmettin Erbakan Üniversitesi Etik Kurulu tarafından onaylandı (onay tarihi ve sayısı: 21.06.2016/2016/701).

\section{Hakem Değerlendirmesi}

Dış bağımsız.

\section{Çıkar Çatışması}

Yazarlar çıkar ilişkisi olmadığını beyan etmişlerdir.

\section{Finansal Destek}

Herhangi bir mali destek alınmamıştır.

\section{Ethics Committee Approva}

The study was approved by Necmettin Erbakan University Ethics Committee. (date and number of approval: 21.06.2016/2016/701).

\section{Peer-review}

Externally peer-reviewed.

\section{Conflict of Interest}

No conflict of interest was declared by the authors.

Financial Disclosure

No financial support has been received.

\section{KAYNAKLAR}

1. DeBusk R, Drory Y, Goldstein I, Jackson G, Kaul S, Kimmel S, et al. Management of sexual dysfunction in patients with cardiovascular disease: recommendations of The Princeton Consensus Panel. Am J Cardiol 2000;86:175-81. [CrossRef]
2. Schwarz ER, Kapur V, Bionat S, Rastogi S, Gupta R, Rosanio $S$. The prevalence and clinical relevance of sexual dysfunction in women and men with chronic heart failure. Int J Impotence Res 2008;20:85-91. [CrossRef]

3. Vicdan N, Özer Z. Miyokard İnfarktüsü ve Cinsel İşlev Bozukluğu. Türk Kardiol Dern Kardiyovasküler Hemşirelik Derg 2011;2:2-6. [CrossRef]

4. Yıldız H, Pınar R. Miyokard İnfarktüslü Hastalarda Cinsel Disfonksiyon. Anadolu Kardiol Derg 2004;4:309_ 17. https://www.journalagent.com/anatoljcardiol/pdfs/ AnatolJCardiol_4_4_309_317.pdf

5. Hoekstra T, Jaarsma T, Sanderman R, van Veldhuisen, DJ, LesmanLeegte I. Perceived sexual difficulties and associated factors in patients with heart failure. Am Heart J 2012;163:246-51. [CrossRef]

6. Nusbaum MR, Helton MR, Ray N. The changing nature of women's sexual health concerns through the midlife years. Maturitas 2004;49:283-91. [CrossRef]

7. Beck AT. An inventory for measuring depression. Arch Gen Psychiatry 1961;4:561-71. [CrossRef]

8. Oken MM, Creech RH, Tormey DC, Horton J, Davis TE, McFadden ET, Carbone PP. Toxicity and Response Criteria of The Eastern Cooperative Oncology Group. Am J Clin Oncol 1982;5:649-55. https://pubmed.ncbi.nlm.nih.gov/7165009/

9. DeBusk R, Drory Y, Goldstein I, Jackson G, Kaul S, Kimmel S, et al. Management of sexual dysfunction in patients with cardiovascular disease: recommendations of the Princeton Consensus Panel. Am J Cardiol 2000;86:175-81. [CrossRef]

10. Metin A, Kayıgil Ö. Kardiyovasküler problemi olan hastalarda cinsel fonksiyonun sağlanması. Erkek cinsel sağlığı. Androloji Bült 2004;16:10-2. http://file.lookus.net/ androlojibulteni/\%C5\%9Eubat-2004-16.Say\%C4\%B1.pdf

11. Hamilton GA, Seidman RN. A comparison of the recovery period for women and men after myocardial infarction. Heart Lung 1992;22:308-15. https://pubmed.ncbi.nlm.nih.gov/8360065/

12. Beutel ME, Stöbel-Richter Y, Brahler E. Sexual desire and sexual activity of men and women across their lifespans: results from a representative German community survey. BJU Int 2008;101:7682. [CrossRef]

13. DeLamater J. Sexual expression in later life: a review and synthesis. J Sex Res 2012;49:125-141. [CrossRef]

14. Kazemi-Saleh D, Pishgoo B, Farrokhi F, Fotros A, Assari S. Sexual function and psychological status among males and females with ischemic heart disease. J Sex Med 2008;5:2330-7. [CrossRef]

15. Addis IB, Christine C, Eric V, Feng L, Stuenkel CA, Hulley S. Sexual activity and function in postmenopausal women with heart disease. Obstet Gynecol 2005;106:121-7. [CrossRef]

16. Schwarz ER, Kapur V, Bionat S, Rastogi S, Gupta R, Rosanio S. The prevalence and clinical relevance of sexual dysfunction in women and men chronic heart failure. Int J Impot Res 2008;20:85-91. [CrossRef]

17. Pelliccia A, Zipes DP, Maron BJ. Bethesda Conference \#36 and the European Society of Cardiology Consensus Recommendations revisited: a comparison of U.S. and European criteria for eligibility and disqualification of competitive athletes with cardiovascular abnormalities. J Am Coll Cardiol 2008;52:1990-6. [CrossRef]

18. Mickley H, Petersen J, Nielsen BL. Subjective consequences of permanent pacemaker therapy in patients under the age of retirement. Pacing Clin Electrophysiol 1989;12:401-5. [CrossRef]

19. Stein R, Sardinha A, Aroujo CGS. Sexual Activity and Heart Patients: A Contemporary Perspective. Can J Cardiol 2016;32:410 20. [CrossRef] 
20. Levine GN, Steinke EE, Bakaeen FG, Bozkurt B, Cheitlin MD, Conti JB, et al. Sexual activity and cardiovascular disease: a scientific statement from the American Heart Association. Circulation 2012;125:1058-72. [CrossRef]

21. Kostis JB, Jackson G, Rosen R, Barrett-Connor E, Billups K, Burnett AL, et al. Sexual dysfunction and cardiac risk (the Second Princeton Consensus Conference). Am J Cardiol 2005;96:313-21. [CrossRef]

22. Lindau ST, Schumm LP, Laumann EO, Levinson W, O'Muircheartaigh CA, Waite LJ. A study of sexuality and health among older adults in the United States. N Engl J Med 2007;357:762-74. [CrossRef]

23. Drory Y, Kravetz S, Weingarten M. Comparison of sexual activity of women and men after a first Acute myocardial infarction. Am J Cardiol 2000;85:1283-7. [CrossRef]

24. Boydak B, Nalbantgil S, Fici F, Nalbantgil I, Zoghi M, Ozerkan F, et al. A randomised comparison of the effects of nebivolol and atenolol with and without chlorthalidone on the sexual function of hypertensive men [published correction appears in Clin Drug Investig 2007;27:864]. Clin Drug Investig 2005;25:409-16. [CrossRef]
25. DeLamater JD, Sill M. Sexual desire in later life. J Sex Res 2005;42:138-49. [CrossRef]

26. Gitlin MJ, Suri R, Altshuler L, Zuckerbrow-Miller J, Fairbanks L. Bupropion- sustained release as a treatment for SSRI-induced sexual side effects. J Sex Marital Ther 2002;28:131-8. [CrossRef]

27. Ma R, Yu J, Xu D, Yang L, Lin X, Zhao F, Bai F. Effect of felodopine with irbesartan or metoprolol on sexual function and oxidative stress in women with essential hypertension. J Hypertens 2012;30:210-16. [CrossRef]

28. Fogari R, Preti P, Zoppi A, Corradi L, Pasotti C, Rinaldi A, Mugellini A. Effect of valsartan and atenolol on sexual behavior in hypertensive postmenopausal women. Am J Hypertens 2004;17:77-81. [CrossRef]

29. Kriston L, Guenzler C, Agvemang A, Bengel J, Berner MM. Effect of sexual function on Health-Related Quality of Life Mediated by Depressive Symptoms in Cardiac Rehabilitation. Findings of the SPARK Project in 493 patients. J Sex Medicine 2010;7:2044-55. [CrossRef] 